\title{
POTENSI BIO-SLURRY DALAM PENINGKATAN KARAKTERISTIK TUMBUH DAN PRODUKSI PASTURA CAMPURAN PADA LAHAN KERING DI DESA SEBUDI KARANGASEM
}

\author{
Suarna, I W., I K.M Budiasa, T.I. Putri, N.P. Mariani, dan M. Hartawan \\ Puslitbang Tumbuhan Pakan Universitas Udayana, Denpasar,Bali \\ Email: suarnawyn@yahoo.com ;puslitbangtp@gmail.com
}

\begin{abstract}
ABSTRAK
Penerapan Biogas kotoran ternak merupakan salah satu upaya mitigasi terhadap perubahan iklim. Di Bali saat in iterdapat 791 unit biogas dengan volume antara 3 sampai $11 \mathrm{~m}^{3}$ perunit biogas. Pemerintah Provinsi Bali mengucurkan dana 10 milya rpertahun untuk mendorong pembangunan dan pemanfaatan biogas. Limbah biogas dikenal sebagai slurry yang selanjutnya dikelola sehingga menghasilkan bioslurry. Penelitian pemanfaatan pupuk bioslurry untuk meningkatkan karakteristik tumbuhdan produksi pasture campuran telah dilaksanakan pada lahan kering di Desa Sebudi Kabupaten Karangasem Provinsi Bali. Hasil penelitian menunjukkan bahwa terjadi peningkatan karakteristik tumbuh tanaman antara lain tinggi tanaman, luas daun spesifik, nisbah daun dengan batang tanaman, serta meningkatnya pemberian pupuk bioslury dapat meningkatkan produksi hijauan total rumput panikum atau paspalum yang ditanam bersama legume. Berat kering oven total hijauan rumput paspalum yang ditanam bersama rumput panikum dan legume Centrocema yang dipupuk dengan pupuk bioslurry yakni masing-masing sebesar 4,75 dan 4,36 tonha ${ }^{-1}$. Penggunaan pupuk organik akan menghasilkan kualitas hijauan yang semakin baik apabila diterapkan pada kombinasi penanaman rumput panikum, paspalum bersama leguminosa.
\end{abstract}

Kata kunci: pasture campuran ,pupuk bioslurry, produksi dan karakteristik tumbuh, lahan kering

\section{PENDAHULUAN}

Salah satu permasalahan dominan yang dihadapi peternak sapi di Bali adalah semakin menurunnya ketersediaan hijauan pakan yang berkualitas, sementara program pengembangan sapi Bali melalui Simantri terus berlanjut sehingga menuntut berbagai faktor pendukung termasuk ketersediaan pakan hijauan. Peningkatan jumlah hijauan pakan membawa konsekuensi dan keharusan membudidayakan tumbuhan pakan, meningkatkan tutupan vegetasi, dan meningkatkan akumulasi karbon pada tumbuhan (As-syakuretal, 2011). Dengan demikian budidaya tanaman pakan juga merupakan upaya strategis untuk mempertahankan dan meningkatkan produksi ternak sekaligus melakukan upaya konservasi terhadap lahan kritis dan mitigasi terhadap perubahan iklim.

Perubahan iklim telah menjadi isu lingkungan global yang akan mengakibatkan munculnya berbagai bencana lingkungan. Deklarasi Bali telah mewajibkan dunia untuk melakukan upaya mitigasi, adaptasi, dan transfer teknologi untuk menanggulangi dampak perubahan iklim. Meningkatkan luasan tutupan vegetasi adalah salah satu upaya untuk berperan serta dalam meningkatkan penyerapan gas rumah kaca (GRK) yang menjadi pemicu munculnya perubahan iklim. Terkait hal tersebut saat ini tumbuhan pakan memiliki peran yang sangat strategis karena selain dapat meningkatkan ketersediaan hijauan pakan juga merupakan aktivitas mitigasi perubahan iklim yang efektif (suarna, 2011).

Tujuan ketiga belas dari tujuh belas Tujuan Pembangunan Berkelanjutan (SDG's) adalah mengambil tindakan mendesak untuk memerangi perubahan iklim dan dampaknya. Terkait perubahan iklim pemerintah Provinsi Bali telah berkomitmen untuk menurunkan emisi gas rumah kaca (GRK) pada tahun 2020 sebesar 12,29\% tanpa adanya intervensi aksi mitigasi dari dunia internasional (businessasusual/ BAU) (Sujayaetal. 2014). Perbaikan pertumbuhan tanaman melalui pemberian pupuk bioslury selain akan dapat meningkatkan pertumbuhan dan produksi serta kualitas hijauan juga sekaligus berkontribusi terhadap pelaksanaan program mitigasi terhadap perubahan iklim.

Berdasarkan hal tersebut sangat diperlukan sebuah penelitian yang bertujuan untuk untuk mendapatkan pengaruh pupuk organik bioslury terhadap karakteristik tumbuh dan

Produksi hijauan pastura campuran pada lahan kering di Desa Sebudi Karangasem. 


\section{METODE PENELITIAN}

Sebuah percobaan lapangan telah dilaksanakan pada lahan kering di Banjar Sogra, Desa Sebudi, Karangasem dari bulan Apri lsampai September 2015. Percobaan menggunakan rancangan acak kelompok dengan 12 perlakuan dan diulang tiga kali. Rancangan perlakuan disusun sebagai berikut:

1. Kombinasi rumput Panikum + Centrosema $+1,5$ kg pupuk kandang sapi

2. Kombinasi rumput Panikum + Centrosema +3 kg pupuk kandang sapi

3. Kombinasi rumput Panikum + Clitoria $+9 \mathrm{~kg}$ bioslury

4. Kombinasi rumput Panikum+ Clitoria $+18 \mathrm{~kg}$ bioslury

5. Kombinasi rumput Paspalum + Centrocema+ 1,5 kg pupuk kandang sapi

6. Kombinasi rumput Paspalum + Centrocema +3 kg pupuk kandang sapi

7. Kombinasi rumput Paspalum + Clitoria $+9 \mathrm{~kg}$ bioslury

8. Kombinasi rumput Paspalum+ Clitoria $+18 \mathrm{~kg}$ bioslury

9. Kombinasi rumput Paspalum+ Panikum+ Centrocema $+1,5 \mathrm{~kg}$ pupuk kandang sapi

10. Kombinasi rumput Paspalum + Panikum + Centrocema $+3 \mathrm{~kg}$ pupuk kandang sapi

11. Kombinasi rumput Paspalum + Panikum + Clitoria $+9 \mathrm{~kg}$ bioslury

12. Kombinasi rumput Paspalum + Panikum+ Clitoria $+18 \mathrm{~kg}$ bioslury

Variabel yang diamati antara lain adalah karakteristik tumbuh tanaman, berat kering oven akar, batang, dan daun tanaman.

Bahan-bahan yang dipergunakan dalam percobaan ini antara lain adalah:

1. Biji rumput (Paspalum atratum dan Panikum maksimum) dan legume (Clitoria ternatea dan Centrocema pubescens) yang ditanam dalam pola asosiasi,

2. Pupuk organik (pupuk kandang dan pupuk bioslurry)

Alat yang digunakan dalam percobaan ini adalah:

1. Soil-pH \& HumidityTester, Model DM-5. Takemura ElectricWorks, LTD. Tokyo Japan.

2. Portable Leaf Area Meter, LAW-A. BeijingKWF Sci-Tech Development Co., Ltd.

3. Timbangan yang berkapasitas $22.6 \mathrm{~kg}$ dengan ketelitian $10 \mathrm{~g}$, yang digunakan untuk menimbang berat hijauan segar;

4. Timbangan Mettler Toledo PB 3002 buatan Switzerland, berkapasitas $500 \mathrm{~g}$ dengan ketelitian 0.01 mg, diperlukan untuk menimbang sampel untuk keperluan analisis kimia.
5. Oven pengering buatan Australia PVY.Ltd.model GC-2, untuk mengeringkan sampel hijauan.

\section{Analisis Data}

Data yang diperoleh terhadap semua variable yang diukur dianalisis dengan sidik ragam univariat (Steel dan Torrei,1989) dan ditampilkan dalam bentuk tabel. Apabila analisis sidik ragam univariat menunjukkan perbedaan yang nyata, maka perbedaan nilai rata-rata perlakuan selanjutnya diuji dengan mempergunakan uji jarak berganda Duncan (Gomez dan Gomez, 1995).

\section{HASIL DANPEMBAHASAN}

Curah hujan rata-rata bulanan selama 10 tahun dari Stasiun pengamat curah hujan pada BPP Kecamatan Selat sebesar $3.628 \mathrm{~mm} \mathrm{th}^{-1}$ dengan 123 hari hujan. Curah hujan terendah pada bulan Agustus sebesar 160 $\mathrm{mm}_{\text {bulan }}{ }^{-1}$ dengan 6 hari hujan dan tertinggi pada bulan Desember sebesar $419 \mathrm{~mm}_{\text {bulan }}{ }^{-1}$ dengan 12 hari hujan. Curah hujan ini mempengaruhi daerah penelitian pada sebagian wilayah di Desa Sebudi.

Tipe iklim diperoleh dengan rasio antara jumlah rerata bulan kering dengan jumlah bulan basah dari masing-masing stasiun penakar curah hujan.Dari hasil perhitungan diperoleh nilai $\mathrm{Q}$ berada diantara $\mathrm{O}<\mathrm{Q}<\mathrm{O}$, 143 artinya tipe iklim menurut Schmidht Ferguson pada kawasan Sub DAS Telagawaja termasuk tipe iklimA (sangatbasah). Namun pada tahun 2014 iklim telah mengalami perubahan dimana hujan turun mulai akhir bulan November. Sedangkan pada tahun 2015 ketika penelitian dilakukan bulan kering lebih panjang daripada bulan basah.

Hasil penelitian menunjukkan bahwa berat kering akar tertinggi dijumpai pada pastura campuran rumput panikum dan paspalum yang dipupuk dengan bioslurry sebanyak $9 \mathrm{~kg}$ (A12). Tetapi berat kering daunnya paling rendah yakni 39,5 g perm ${ }^{2}$. Perlakuan A9 dan A1o memberikan produksi hijauan (batang dan daun) yang lebih tinggi daripada perlakuan lainnya. Tingginya produksi tersebut disebabkan oleh adanya pemberian pupuk pupuk kandang sapi yang mampu menyediakan kondisi yang baik bagi perkembangan jazad mikro dan makro tanah. Pupuk kandang sapi yang digunakan adalah pupuk yang sudah matang dan hamper menyerupai tanah sehingga pelepasan hara dari pupuk tersebut akan lebih cepat terjadi dibandingkan dengan menggunakan pupuk bioslurry.

Luas daun rumput panikum dan rumput paspalum tertinggi apabila kedua rumput tersebut ditanam bersama legume klitoria dan mendapat tambahan pupuk sebanyak18 kg bioslury (Tabel1). Penggunaan pupuk kandang pada centrocema memberikan luas daunyang lebih luas bila centrocema ditanam bersama rumput paspalum dan panikum daripada centrocema 
Tabel 1. Luas Daun Tanaman

\begin{tabular}{|c|c|c|c|c|c|c|c|}
\hline \multicolumn{2}{|c|}{ Panikum } & \multicolumn{2}{|c|}{ Paspalum } & \multicolumn{2}{|c|}{ Centrosema } & \multicolumn{2}{|c|}{ Clitoria } \\
\hline Perlakuan & Luas Daun & Perlakuan & Luas Daun & Perlakuan & Luas Daun & Perlakuan & Luas Daun \\
\hline \multicolumn{8}{|c|}{ 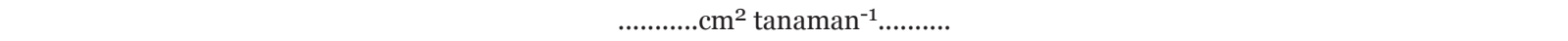 } \\
\hline A1 & 2447,36 & A5 & 3001,44 & $\mathrm{~A} 1$ & 208,00 & A3 & 380,00 \\
\hline A2 & 2206,67 & A6 & 2835,59 & A2 & 212,78 & $\mathrm{~A} 4$ & 231,55 \\
\hline A3 & 2055,56 & A7 & 2274,00 & A5 & 253,33 & A7 & 248,54 \\
\hline $\mathrm{A} 4$ & 3813,81 & A8 & 2793,72 & A6 & 234,00 & A8 & 253,33 \\
\hline A9 & 1212,80 & A9 & 2378,27 & A9 & 401,67 & A11 & 234,17 \\
\hline A10 & 596,88 & A10 & 2461,89 & A10 & 273,33 & A12 & 360,00 \\
\hline A11 & 983,54 & A11 & 2665,82 & & & & \\
\hline A12 & 1030,15 & A12 & 1594,01 & & & & \\
\hline
\end{tabular}

ditanam bersama rumput paspalum saja atau dengan rumput panikum saja. Hal tersebut kemungkinan disebabkan centrocema lebih efisien memanfaatkan pupuk karena rumput panikum yang ditanam bersama paspalum akan memberikan tutupan vegetasi yang lebih merata.

Tabel 2 menunjukkan bahwa kombinasi rumput Paspalum dengan clitoria dan dipupuk dengan18 $\mathrm{kg}$ bioslury memberikan nisbah daun dengan batang tanaman yang sama dengan kombinasi rumput Paspalum dengan Panikum disertai dengan legume Centrocema dan 1,5 kg pupuk kandang sapi. Penggunaan pupuk bioslury memberikan nisbah daun dengan batang dan nisbah pupus dengan akar yang lebih baik dan peningkatan dosis biolury juga memberikan nisbah yang lebih tinggi.

Peningkatan pemberian pupuk kandang sapi dan atau pupuk bioslurry dapat memberikan hasil hijauan yang lebih tinggi pada pasture campuran legume dengan panikum, legume dengan paspalum, dan pasture campuran legume dengan panikum dan paspalum. Legum clitoria memberikan hasil hijauan yang lebih tinggi apabila ditanam bersama panikum atau paspalum, tetapi produksi hijauan clitoria akan menurun bila ditanam bersama panikum dan paspalum. Tanaman legume memberikan kontribusi hara kepada tanaman rumput yang hidup berdampingan dengan legume. Hal tersebut diungkapkan oleh Alison (1994) dan Herryawan (2013). Hal seBaliknya terjadi pada centrocema yang memberikan hasil lebih tinggi pada pasture campuran bersama panikum dan paspalum. Hal tersebut sangat dimungkinkan oleh karena sifat tumbuh tanaman berbeda dan klitoria membutuhkan sinr matahari yang lebih banyak, centrocema lebih tahan terhadap naungan dibandingkan dengan klitoria. Penomena tersebut sesuai dengan hasil penelitian Suarna et al.(2014 $\left.4^{\mathrm{a}}\right)$.

Berat kering oven total hijauan rumput paspalum yang ditanam bersama rumput panikum dan legume Centrocema yang dipupuk dengan pupuk kandang sapi (A9danA10) lebih tinggi daripada perlakuan lainnya yakni masing-masing sebesar 4,75 dan 4,36 tha ${ }^{-1}$. Sedangkan berat kering oven total hijauan paspalum yang ditanam bersama legume clitoria yang dipupuk dengan bioslury adalah tertinggi yakni sebesar 5,1 tha1. Hal tersebut sesuai dengan hasil analisis terhadap volume dan kerapatan tanaman yang menunjukkan hasil tertinggi pada asosiasi rumput paspalum dengan legume clitoria (Suarnaetal. $\left(2014^{\mathrm{b})}\right)$.

Tabel 2. Nisbah Daun dan Batang Tanaman dan Nisbah Pupus dengan Akar Tanaman

\begin{tabular}{ccccc}
\hline Perlakuan & L/S Ratio & \multicolumn{3}{c}{ T/R Ratio } \\
\hline A1 & 0,226 & $\mathrm{~b}$ & 0,613 & $\mathrm{~b}$ \\
A2 & 0,464 & $\mathrm{~b}$ & 1,042 & $\mathrm{ab}$ \\
A3 & 0,589 & $\mathrm{~b}$ & 0,530 & $\mathrm{~b}$ \\
A4 & 0,522 & $\mathrm{~b}$ & 1,239 & $\mathrm{a}$ \\
A5 & 1,845 & $\mathrm{a}$ & 0,682 & $\mathrm{~b}$ \\
A6 & 1,007 & $\mathrm{ab}$ & 1,014 & $\mathrm{ab}$ \\
A7 & 0,618 & $\mathrm{ab}$ & 2,395 & $\mathrm{a}$ \\
A8 & 1,241 & $\mathrm{a}$ & 0,982 & $\mathrm{ab}$ \\
A9 & 1,393 & $\mathrm{a}$ & 1,620 & $\mathrm{a}$ \\
A10 & 0,935 & $\mathrm{ab}$ & 1,340 & $\mathrm{a}$ \\
A11 & 0,758 & $\mathrm{ab}$ & 0,662 & $\mathrm{~b}$ \\
A12 & 0,781 & $\mathrm{ab}$ & 1,020 & $\mathrm{ab}$ \\
\hline
\end{tabular}

Tabel 3. Berat Kering Oven Akar, Batang dan DaunTanaman Perlakuan Akar Batang Daun

\begin{tabular}{|c|c|c|c|c|c|c|}
\hline \multicolumn{7}{|c|}{$\ldots \ldots \ldots \ldots . . \mathrm{gm}^{-2} \ldots \ldots \ldots \ldots$} \\
\hline A1 & 23,90 & $\mathrm{c}$ & 11,94 & $\mathrm{c}$ & 2,70 & $\mathrm{e}$ \\
\hline A2 & 27,25 & $\mathrm{c}$ & 19,40 & $\mathrm{c}$ & 9,00 & $\mathrm{e}$ \\
\hline A3 & 34,65 & $\mathrm{c}$ & 11,55 & $\mathrm{c}$ & 6,80 & e \\
\hline A4 & 22,35 & $\mathrm{c}$ & 18,20 & $\mathrm{c}$ & 9,50 & $\mathrm{e}$ \\
\hline A5 & 55,03 & $\mathrm{~b}$ & 13,20 & $\mathrm{c}$ & 24,35 & $\mathrm{c}$ \\
\hline A6 & 66,65 & $\mathrm{ab}$ & 33,65 & $\mathrm{bc}$ & 33,90 & $\mathrm{bc}$ \\
\hline A7 & 53,25 & $\mathrm{~b}$ & 78,85 & $\mathrm{a}$ & 48,70 & $a b$ \\
\hline A8 & 79,95 & $\mathrm{a}$ & 35,05 & $\mathrm{~b}$ & 43,50 & $\mathrm{~b}$ \\
\hline A9 & 73,25 & $a b$ & 49,60 & $\mathrm{ab}$ & 69,10 & $\mathrm{a}$ \\
\hline A10 & 81,40 & $\mathrm{a}$ & 56,35 & $\mathrm{a}$ & 52,70 & $\mathrm{a}$ \\
\hline A11 & 60,80 & $a b$ & 22,90 & $\mathrm{bc}$ & 17,35 & $\mathrm{~d}$ \\
\hline A12 & 88,30 & $\mathrm{a}$ & 50,60 & $\mathrm{a}$ & 39,50 & $\mathrm{~b}$ \\
\hline
\end{tabular}

Berdasarkan Tabel 1 dapat dinyatakan bahwa penanaman legume akan dapat meningkatkan pertumbuhan dan hasil tanaman rumput. Rumput paspalum memberikan respons pertumbuhan dan produksi yang lebih baik daripada rumput panikum. Rumput panikum yang ditanam bersama paspalum 
dan legume klitoria atau centrosema memberikan produksi hijauan yang lebih baik daripada ditanam bersama legume saja.

\section{KESIMPULAN}

Berdasarkan hasil penelitian di atas dapat disimpulkan bahwa meningkatnya pemberian pupuk kandang sapi dan pupuk bioslury dapat meningkatkan produksi hijauan total rumput panikum atau paspalum yang ditanam bersama legume. Berat kering oven total hijauan rumput paspalum yang ditanam bersama rumput panikum dan legume Centrocema yang dipupuk dengan pupuk kandang sapi yakni masingmasing sebesar4,75 dan 4,36 tha ${ }^{-1}$. Penggunaan pupuk organik akan menghasilkan kualitas hijauan yang semakin baik apabila diterapkan pada kombinasi penanaman rumput panikum, paspalum dan leguminosa.

\section{REFERENSI}

Alison, M.W. and W.D. Pitman.1995. Legume use in pastures. Louisiana Agric. 38:16-17.

As-syakur, A.R. I.W. Suarna, I.W. Rusna, I.N. Dibia. 2011. Pemetaan Kesesuaian Iklim Tanaman Pakan serta Kerentanannya Terhadap Perubahan Iklim dengan Sistem Informasi Geografi (SIG) di Provinsi Bali. Jurnal Pastura, 1:1(9-15).

Gomez,K.A. dan A.A. Gomez. 1995 .Prosedur statistic untuk penelitian pertanian. Terjemahan E.Sjamsuddin dan J. S. Baharsjah. UI-Press. Jakarta, halaman 87-219.

Herryawan, K.M. 2013. Mekanisme Transfer Nutrisi dari Legum keRumput yang Diinokulasi FMA (Ifapet). Proc SeminarTumbuhan Pakan HITPI,
28 Juni 2013 di Hotel Inna Bali, Denpasar. Halaman 118-131

Miller, D.A. 1984. Forages crops. McGraw-Hill. Inc. New York, p. 53-60.

Sheoran, V., A.S.Sheoran, and P. Poonia. 2010. Soil Reclamation Of A bandoned Mine Land By Revegetation: A Review. International Journal Of Soil, Sediment And Water, Vol 3 No.2.

Skerman, P.J. 1977.Tropical forage legume. FAO. Rome, p. 69-89.

Steel, R.G. D. and J.H. Torrie. 1989. Prinsip dan prosedur statistika: Suatu pendekatan biometrik. Alihbahasa: Bambang Sumantri. Edisikedua. PT.Gramedia. Jakarta, halaman 148-190.

Suarna, I W.2011 .Peran Tanaman Pakan dalam Mitigasi dan Adaptasi terhadap Perubahan Iklim. Prosiding, Semiloka Nasional Himpunan Ilmuwan Tanaman Pakan Indonesia (HITPI), 5 Nopember2010 di Universitas Udayana

Suarna,I W., N.N. Candraasih K.,dan M.A.P. Duarsa.2014 ${ }^{\mathrm{a})}$. Model Asosiasi Tanaman Pakan Adaptif Untuk Perbaikan Lahan Pasca Tambang Di Kabupaten Karangasem. J. Bumi Lestari. 4(1):9-14.

Suarna, I W., N.N. Candraasih K., A.A.A.S. Trisnadewi, dan M.A.P. Duarsa. 2014 ${ }^{\text {b) }}$. Produktivitas Rumput Panikum dan Paspalum Dalam Kombinasinya dengan Legum pada Lahan Kering. Prosiding Semnas III HITPI di Bukit Tinggi. 211- 216

Usha P. Pillai-Mc Garry A, Craig Lockhart Band David Mulligan. 2010. Soil factorsaffecting vegetation establishment after sand mining on North Stradbroke Island. 19th World Congress of Soil Science, Soil Solutions for a Changing World 1-6 August2010, Brisbane, Australia. Published on DVD. 